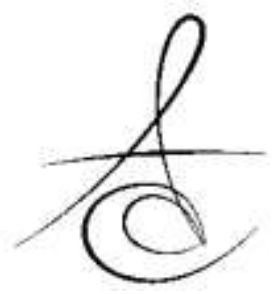

\section{GÖRSEL ANALOG SKALASI KULLANILARAK UZMAN DİŞ HEKİMLERİ VE DİŞ HEKİMLİĞİ ÖĞRENCİLERİNİN ESTETİK PARAMETRELERİNİN ALGILANMASINDAKİ FARKLILIĞIN İNCELENMESİ}

\author{
EXAMINATION OF THE DIFFERENCE IN PERCEPTION OF ESTHETIC \\ PARAMETERS OF SPECIALIST DENSTIST AND DENTAL STUDENTS BY USING \\ VISUAL ANALOG SCALE
}

Arş. Gör. Dt. Sümeyye CANSEVER*

Arş. Gör. Dt. Harun Reşit BAL*

Prof. Dr. Nuran YANIKOĞLU*

Makale Kodu/Article code: 3968

Makale Gönderilme tarihi; 04.02.2019

Kabul Tarihi: 11.12.2019

DOI : $10.17567 /$ ataunidfd.658038

Sümeyye Cansever: ORCID ID: 0000-0001-6415-6491

Harun Reşit Bal: ORCID ID: 0000-0003-1875-9464

Nuran Yanıkoğlu: ORCID ID: 0000-0001-7677-1248

öz

Amaç: Bütün insanlar estetik olarak hoş yüz özelliklerine sahip olmayı istemektedirler, bunların içinde de en çok arzuladıkları güzel bir gülümsemedir. Son yıllarda dental estetiğe olan ilgi giderek artmaya başlamıştır. Diş hekimleri ve halktan bireyler arasında estetik değerlendirmelerde farklılıklar olduğu görülmektedir. Bu çalıșmada uzman diş hekimleri ve diş hekimliği öğrencilerinin hastaların tam gülümseme esnasında, değişen estetik parametrelerinin belirlenerek estetik algılarının ve çekici bir gülümsemenin nelere sahip olması gerektiğinin değerlendirilmesi amaçlanmıștır.

Materyal ve Metod: Hastalardan gülümseme halinde çekilmiş 24 fotoğraf, uzman diş hekimlerine ve diş hekimliği öğrencilerine rastgele bir sırayla gösterilip çekiciliklerine göre değerlendirmeleri istenmiştir. Çalışmaya katılan kişilerden orta hat kayması, okluzal düzlem eğimi, dişeti görünürlük(gummy smile) miktarı ve santral dişlerin diğer dişlere göre oranlarının düzenlemesi yapılmış fotoğrafları değerlendirmeleri istenmiştir. Fotoğraflarda $0.5^{\prime} \mathrm{er} \mathrm{mm}$ artan oranlarla Adobe Photoshop programı kullanılarak değişiklikler uygulanmıştır.

Bulgular: Uzman diş hekimleri, 1. ve 5. Sınıf öğrencilerinin değişen estetik parametreleri algılarının incelendiği çalışmada istatiksel analiz değerlendirmeleri sonucunda gruplar arasında istatiksel olarak anlamlı farklııklar bulundu $(p<0,05)$.

Sonuçlar: Çalışmada; eğitim seviyesi ile bireylerdeki estetik algının değiştiği, 0,5 mm'lik değişimlerin uzman diş hekimleri tarafından daha doğru saptanabildiği tespit edildi.

Anahtar Kelimeler: Görsel analog skalası, Estetik, Orta hat sapması, Gummy smile

\title{
ABSTRACT
}

Aim: All people want to have aesthetically pleasing facial features, among them a beautiful smile that they most desire. In recent years, interest in dental aesthetics has begun to grow. It is seen that there are differences in aesthetic evaluations between dentists and individuals. It was aimed to evaluate the aesthetic perceptions and what an attractive smile should have in order to determine the changing aesthetic parameters during the full smile of the patients by profesional dentists and dental students.

Material and Methods: 24 photos taken in smiles from the patients were asked to be shown to the profesional dentists and dental students in random order and evaluated according to their attractiveness. Participants in the study were asked to rate the images of midline deviation, occlusal plane inclination, gummy smile and ratio of central teeth to other teeth. Photos have been modified by using Adobe Photoshop program in increments of $0.5 \mathrm{~mm}$.

Results: A statistically significant difference was found between the groups in terms of statistical analysis evaluations in the study which examined the perception of changing aesthetic parameters of first and fifth grade students of specialist dentists. ( $\mathrm{p}<0,05)$

Conclusions: In this study was determined that the aesthetic perception in the individuals changed with the education level and the changes in the $0.5 \mathrm{~mm}$ were more accurate by the expert dentists.

Keywords: Visual analogue scale, Esthetic, Midline deviation, Gummy smile

* Atatürk Üniversitesi Diș Hekimliği Fakültesi Protetik Diș Tedavisi Anabilim dalı, Erzurum

Kaynakça Bilgisi Cansever S, Bal HR, Yanıkoğlu N. Görsel analog skalası kullanılarak uzman diş hekimleri ve diş hekimliği öğrencilerinin estetik parametrelerinin algılanmasındaki farkllı̆ı̆ın incelenmesi. Atatürk Üniv Diş Hek Fak Derg 2020; 30: 607-13.

Citation Information: Cansever S, Bal HR, Yanikoglu N. Examination of the difference in perception of esthetic parameters of specialist denstist and dental students by using visual analog scale. J Dent Fac Atatürk Uni 2020; 30: 607-13. 


\section{GİRIŞ}

Binlerce yıldır insanlar, insan güzelliğini oluşturan şeyin ne olduğuyla ilgili kafa karışıklığıyla mücadele etmektedirler. Güzellikteki kanunlar kültürden kültüre ${ }^{1-4}$, zamandan zamana farklılıklar göstermektedir $^{5}$. Bütün insanlarda estetik olarak hoşa giden yüz hatları ve çekici bir gülümseme en çok aranan ve arzulanan özelliklerdir.

Günümüzde hastalar, hekimlerden estetik olarak sosyal medyada, televizyon programlarında karşılaştıkları mükemmel gülüşleri talep etmeye başlamışlardır. Bu yüzden hastalar sadece estetik sebeplerle diş hekimi kliniklerine etkileyici, hoş bir gülüş, daha beyaz, daha simetrik dişler için başvurmaya başlamışlardır. Ancak güzellik kesin bir kavram olmamakla birlikte kültüre, bireysel faktörlere ve etnik faktörlere bağlı olarak değişmektedir ${ }^{6}$.

Dale Carregre, insanları etkilemenin en etkili ve kolay yolunun gülümseme olduğunu belirtmiştir? ${ }^{7}$. Çekici ve hoş bir gülümseme insan ilişkilerinde pozitif bir etki oluştururken sosyal ortamda da kabul görmeyi kolaylaştırmaktadır.

Gülümseme analizinde, gülümsemeyle dişlerin ve dişetlerinin görünüm miktarı, gülümseme arkı, diş oranları, dişeti yüksekliği ve konturu, diş orta hattı ile yüz orta hattının ilişkisi, okluzal düzlemin interpupillar ve komissural hat ile ilişkisi, dişlerin şekli ve rengi değerlendirilmelidir ${ }^{8}$. Estetik olarak hoş bir gülüş bu değişkenlerin birbirleriyle uyumlu ve simetrik olmasına bağlıdır.

Estetik diş hekimliği bilgisini genişletmek amacıyla gülme arkı $^{9-11}$, farklı tip bukkal koridorlar ${ }^{10-12}$, orta hat diastemasının varlığı ${ }^{11,13,14}$, üst anterior dişlerdeki dental ve gingival asimetrinin varlığıyla1, 7, 9, ${ }^{15}$ diğerleri arasında çeşitli gülümseme parametreleri araştırılmıştır.

Chiche ve arkadaşlarına ${ }^{16}$ göre orta hatta yaklaştıkça simetriye olan intiyaç artarken, çözümü zor olan asimetriler orta hattan uzaklaştıkça daha kabul edilebilir olmaktadır.

Yüzün uyum içerisinde olması için frontal perspektiften bakıldığında transverse okluzal düzlemin, interpupillar düzlem, komissural düzlem gibi yüzün horizontal referans düzlemlerine paralel olması gerekmektedir.

Silva ve ark'nın ${ }^{17}$ yaptığı bir çalışmada farklı yüz ve diş uyuşmazlıklarının estetik etkisini incelediklerinde insanların büyük çoğunluğu tarafından $3^{\circ}$ lik okluzal düzlem eğimlerini fark edebileceklerinin sonucuna varılmıştır. Diğer çalışma sonuçlarına göre eğim 2 ila $4^{0}$ yi aşmadığı sürece insanlar tarafından fark edilemeyeceği bulunmuştur.

Asimetri estetik olarak hoşa gide yüzlerde bile tipik bir bulgudur ${ }^{18}$. Yüzdeki asimetrilerin varyasyonları bilimsel olarak normal ve anormal asimetrileri ayırmak için tanımlanan nesnel ölçütlerin yokluğuna rağmen estetik sorumluluk olarak kabul edilmemektedir ${ }^{17}$.

Uzman diş hekimleri ve genel popülasyon arasında gülme estetik tercihleri açısından farklılıklar olduğu görülmüştür. ${ }^{19}$ Diş hekimliği uzmanlık dalları içinde ortodontistler diğer diş hekimlerine göre daha analitiktirler ${ }^{13}$.

Asimetrik değişiklikler sadece diş hekimleri için değil aynı zamanda genel popülasyon için dişleri çekici olmaktan uzaklaştırır ${ }^{13}$. Görsel analog skalası yüz ve diş estetiğinin değerlendirilmesinde kullanılabilir basit ve güvenilir bir yöntem olarak kabul edilmektedir ${ }^{19}$.

Bu bilgilerin önderliğinde çalışmada, diş hekimliği uzmanlık alanlarının ve diş hekimliği öğrencilerinin değişen estetik parametreleri algılamalarının incelenmesi amaçlanmıştır. Çalışmamızın hipotezi, uzman diş hekimlerinin 5. sınıf öğrencilerine göre ve 5. sınıf öğrencilerinin 1. sınıf öğrencilerine göre estetik algılarının daha duyarlı olacağı yönündedir.

\section{MATERYAL ve METOD}

Çalışmamızın protokolünde üç farklı grubun görsel analog skalası kullanılarak estetik algılarının değerlendirilmesi yapılmıştır. Çalışmanın birinci grubu diş hekimliği birinci sınıf öğrencilerinden, ikinci grubu beşinci sınıf öğrencilerinden ve üçüncü grubu uzman diş hekimlerinden 50'şer kişi katılmıştır. Toplamda 4 parametreden oluşan 24 fotoğraf çalışmaya dahil edilmiştir. Fotoğraflar hastaların tam gülümseme pozisyonlarında, çene ve burun ucunu kapsayacak şekilde çekilmiş olup, hastaların diğer fiziksel özellikleri değerlendirme dışında bırakılmış ve katıımcıların yargılarının etkilenmesi minimalize edilmeye çalışılmıştır. Hastalara Onam formu imzalatılmış ve çalışmanın etik kurul raporu Atatürk Üniversitesi Diş Hekimliği Fakültesi Etik kurulundan alınmıştır. Fotoğraflar adobe photoshop programı üzerinde gülümseme estetiğinin tutarsızlıklarına göre 0.5 ila $1 \mathrm{~mm}$ artarak değişen derecelerde yeniden düzenlenmiştir. Orta hat sapması, okluzal düzlem eğimi, gummy smile miktarı, santral dişlerin diğer dişlere göre kron boyu uzunlukları gülümseme estetiğinde değerlendirilecek parametreler olarak seçilmiştir. 
Orta hat sapması, $0.5 \mathrm{~mm}$ artan derecelerde hastanın sağına doğru düzenlenmiştir. Üst dudağın filtrumu sabitlenip, referans olarak kullanılmıştır (Şekil 1).

Santral dişler, $0.5 \mathrm{~mm}$ artan derecede uzunlukları düzenlenmiş olup, diş uzunluklarının referans noktaları zenit noktaları olarak şeçilmiştir (Şekil 2).

Okluzal düzlem eğimi 0.5 derece arttırarak düzenlenmiştir. Referans düzlem komissuralardan geçen çizgi olarak kabul edilmiştir (Şekil 3).

Gummy smile miktarı $0.5 \mathrm{~mm}$ arttırılarak düzenlenmiştir. Üst dudak pozisyonunun maksiller santral dişlerin gingival marjinleriyle ilişkisine dayandırılmıştır (Şekil 4).

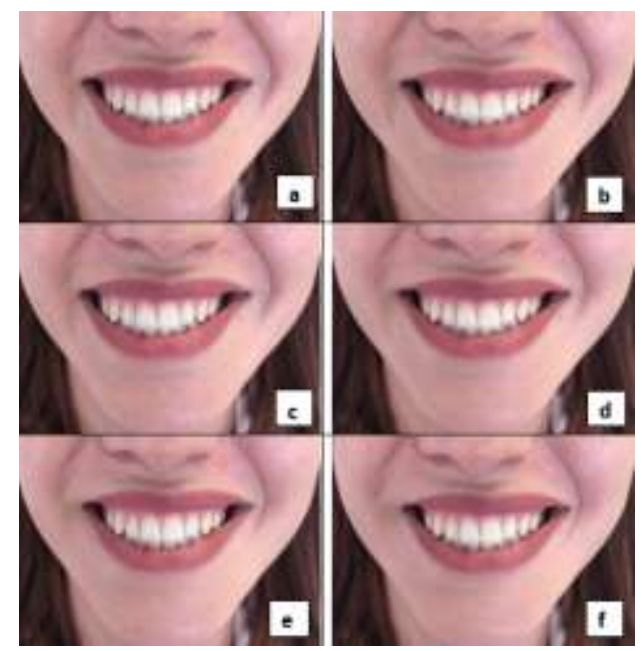

Şekil 1. Orta hat kayması; maksiller santraller arasından geçen düzlemin vertikal düzleme, orijinal (a), 0,5 mm (b), 1 $\mathrm{mm}$ (c), $1,5 \mathrm{~mm}$ (d), $2 \mathrm{~mm}$ (e) ve $2,5 \mathrm{~mm}$ (f) yaklaşan fotoğrafları.

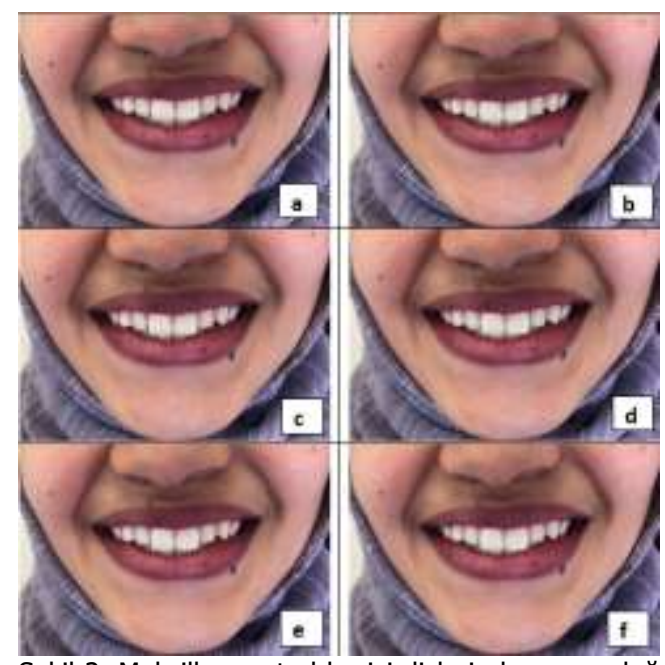

Şekil 2. Maksiller santral kesici dişlerin kron uzunluğu, orijinal (a), 0,5 mm (b), $1 \mathrm{~mm}$ (c), 1,5 mm (d), $2 \mathrm{~mm}$ (e) ve $2,5 \mathrm{~mm}$ (f) artma gösteren fotoğraflar.

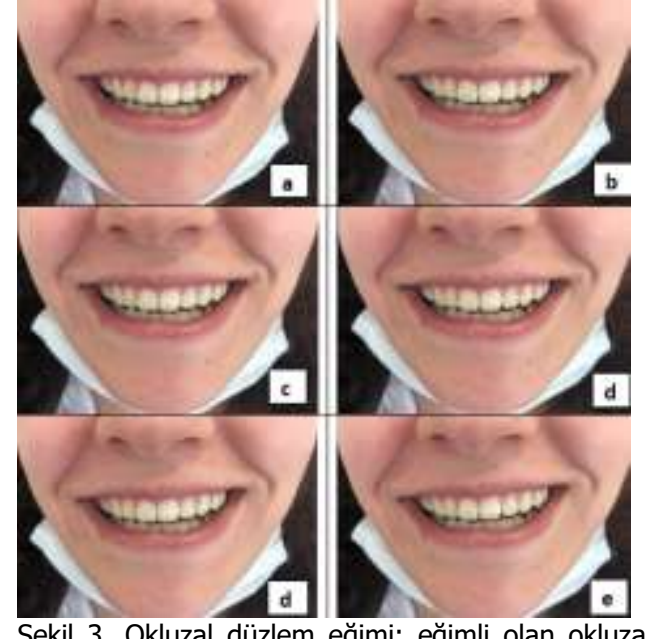

Şekil 3. Okluzal düzlem eğimi; eğimli olan okluzal düzlemin horizontal düzleme, orijinal (a), 0,5 mm (b), $1 \mathrm{~mm}$ (c), 1,5 $\mathrm{mm}(\mathrm{d}), 2 \mathrm{~mm}$ (e) ve 2,5 mm(f) yaklaşan fotoğrafları.

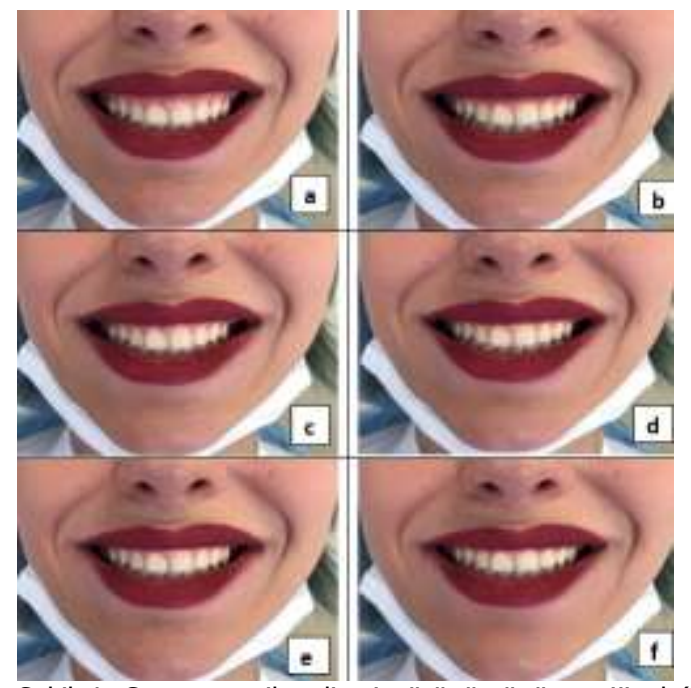

Şekil 4. Gummy smile; dişeti görünümünün, orijinal (a), 0,5 $\mathrm{mm}$ (b), $1 \mathrm{~mm}$ (c), $1,5 \mathrm{~mm}$ (d), $2 \mathrm{~mm}$ (e) ve $2,5 \mathrm{~mm}$ (f) azalma gösteren fotoğrafları.

Bütün fotoğraflar, artan değerlerine göre a dan $f^{\prime}$ ye kadar gruplandırıldı, fotoğraflar 4 grup halinde ayrıldı ve rastgele karıştırıldı. Her katılımcıya VAS içeren değerlendirme formları dağıtıldı. VAS $100 \mathrm{~mm}$ uzunluğunda düzenlenmiştir. Skalanın soluna 0'a doğru gidilmesi değerlendirmede "en az estetik", sağa doğru ve skalanın sonuna doğru gidilmesi 100 değeri "en iyi estetik" olduğunu belirtmektedir. Fotoğraflara 20 sn bakıldıktan sonra katılımcılardan, gülümseme fotoğraflarını kendi kişisel estetik algılarına göre değerlendirip VAS üzerinde işaretlemeleri istendi. VAS üzerinde yapılan işaretlemeler dijital kumpas ile ölçülerek not edildi.

\section{İstatiksel analiz}

İstatiksel analiz SPSS (version 15.0, SPSS Inc., Chicago, Illinois, USA) paket programı ile yapılmıştır.

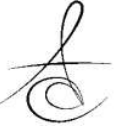


Her grup için VAS değerleri ve standart sapmalar belirlenmiştir. Tek yönlü varyans analizi (ANOVA) her grubun, her sapma seviyesini nasıl derecelendirdiğini değerlendirmek için kullanılmıştır. 3 hipotezin de test edilebilmesi için önemli genel testleri bir dizi post-hoc çoklu karşılaştırma (LSD and Bonferroni düzeltmesi) testleri takip etmiştir. Bonferroni yöntemi ile tespit edilemeyeceğinden LSD, yakından ilişkili iki meslek olan, protetik diş tedavisi ve diğer uzman diş hekimleri arasındaki herhangi bir anlamlılık seviyesini tespit etmek için kullanıldı.

\section{BULGULAR}

Orta hat sapmasının değerlendirildiği fotoğraflarda, ortalama en yüksek VAS değeri uzman diş hekimleri ve 1 sınıf öğrencilerinin $f$ resminde tespit edilmiştir (Tablo 1). Gruplar arasında istatiksel olarak anlamlı fark yoktur. 1. sınıf öğrenci gruplarının $a, b$ ve c fotoğrafları ile d, e, ve f fotoğrafları arasında, 5. Sınıf öğrenci ve uzman diş hekimleri gruplarında $a, b, c$ ve d fotoğrafları ile e ve f fotoğrafları arasında anlamlı fark bulunmuştur.

Tablo 1. Orta hat sapmasının gruplara göre ortalama, standart sapma ve anlamlılık değerleri.

\begin{tabular}{|c|c|c|c|c|c|c|c|c|c|}
\hline & \multicolumn{3}{|c|}{ 1. Sınıf Öğrencileri } & \multicolumn{3}{|c|}{ 5. Sınıf Öğrencileri } & \multicolumn{3}{|c|}{ Uzman Diş Hekimler } \\
\hline & Ort. & SD & $\mathrm{p}$ & Ort. & SD & $\mathrm{p}$ & Ort. & SD & $\mathrm{p}$ \\
\hline Fotoğraf a & 45,31 & 24,29 & $0,18^{\mathrm{aA}}$ & 38,21 & 21,15 & $0,24^{\mathrm{aA}}$ & 26,52 & 25,96 & $0,32^{\mathrm{aA}}$ \\
\hline Fotoğraf b & 44,16 & 24,79 & $0,12^{\mathrm{aB}}$ & 37,52 & 22,28 & $0,45^{\mathrm{aB}}$ & 32,54 & 24,57 & $0,29^{\mathrm{aB}}$ \\
\hline Fotoğraf c & 55,48 & 22,30 & $0,25^{\mathrm{aC}}$ & 39,45 & 23,47 & $0,28^{a c}$ & 36,02 & 25,87 & $0,47^{\mathrm{aC}}$ \\
\hline Fotoğraf $\mathbf{d}$ & 70,11 & 21,87 & $0,06^{\mathrm{bD}}$ & 45,24 & 23,30 & $0,36^{\mathrm{aD}}$ & 35,28 & 25,53 & $0,14^{\mathrm{aD}}$ \\
\hline Fotoğraf e & 72,16 & 32,42 & $0,08^{\mathrm{bE}}$ & 61,59 & 26,74 & $0,11^{\mathrm{bE}}$ & 72,53 & 32,12 & $0,09^{\mathrm{bE}}$ \\
\hline Fotoğraf f & 73,24 & 31,56 & $0,09^{\mathrm{bF}}$ & 63,81 & 25,78 & $0,06^{\mathrm{bc}}$ & 71,45 & 31,75 & $0,05^{\mathrm{bF}}$ \\
\hline
\end{tabular}

Büyük harfler yatay anlamlılığı, küçük harfler dikey anlamlılığı belirtmektedir.

Santral dişlerin boyutunun değerlendirildiği fotoğraflarda, ortalama en yüksek VAS değeri uzman diş hekimlerinin değerlendirdiği, $2 \mathrm{~mm}$ ve $2,5 \mathrm{~mm}$ uzatılan fotoğraflarda, ortalama en düşük VAS değeri ise uzman diş hekimlerinin değerlendirdiği orijinal fotoğraflarda bulundu (Tablo 2). Santral dişlerin boyutunun değerlendirildiği orijinal fotoğraf ile kron boyu $0,5 \mathrm{~mm}, 1 \mathrm{~mm}$ ve $1,5 \mathrm{~mm}$ arttırılan fotoğrafların arasında hiçbir grupta istatiksel olarak anlamlı bir fark bulunmazken; kuron boyu $2 \mathrm{~mm}$ ve 2,5 mm arttırılan fotoğraflar ile orjinalleri arasında istatiksel olarak anlamlı bir fark bulunmuştur.

Okluzal düzlem eğiminin değiştirildiği fotoğraflarda en yüksek VAS değeri uzman diş hekimlerinin değerlendirdiği f fotoğrafında tespit edildi (Tablo 3). Her üç grupta da orijinal fotoğraf ile okluzal düzlemin $0,5 \mathrm{~mm}$ ve $1 \mathrm{~mm}$ düzeltildiği gruplar arasında anlamlı fark bulunmazken; 1,5, 2 ve 2,5 mm düzeltilen gruplar arasında anlamlı fark tespit edildi.

Tablo 2. Santral dişlerin boyutunun gruplara göre ortalama, standart sapma ve anlamlılık değerleri.

\begin{tabular}{|c|c|c|c|c|c|c|c|c|c|}
\hline & \multicolumn{3}{|c|}{ 1. Sınıf Öğrencileri } & \multicolumn{3}{|c|}{ 5. Sınıf Öğrencileri } & \multicolumn{3}{|c|}{ Uzman Diş Hekimleri } \\
\hline & Ort. & $\mathrm{SD}$ & $p$ & Ort. & $\mathrm{SD}$ & $p$ & Ort. & SD & $p$ \\
\hline Fotoğraf a & 44,21 & 23,48 & $0,58^{\mathrm{aA}}$ & 32,12 & 22,25 & $0,35^{\mathrm{aA}}$ & 26,52 & 22,85 & $0,21^{\mathrm{aA}}$ \\
\hline Fotoğraf $b$ & 44,18 & 24,56 & $0,11^{\mathrm{aB}}$ & 31,25 & 20,20 & $0,81^{\mathrm{aB}}$ & 33,25 & 23,53 & $0,18^{\mathrm{aB}}$ \\
\hline Fotoğraf c & 43,58 & 22,45 & $0,88^{\mathrm{aC}}$ & 34,52 & 22,87 & $0,48^{\mathrm{aC}}$ & 36,02 & 26,87 & $0,56^{\mathrm{aC}}$ \\
\hline Fotoğraf d & 44,01 & 21,23 & $0,16^{\mathrm{aD}}$ & 44,32 & 21,00 & $0,56^{\mathrm{aD}}$ & 45,28 & 25,84 & $0,23^{\mathrm{aD}}$ \\
\hline Fotoğraf e & 56,05 & 32,20 & $\overline{0,04^{\mathrm{bE}}}$ & 58,95 & 25,84 & $0,03^{\mathrm{bE}}$ & 61,43 & 32,32 & $0,04^{\mathrm{bE}}$ \\
\hline Fotoğraf f & 55,05 & 31,45 & $0,04^{\mathrm{bF}}$ & 62,55 & 29,58 & $0,04^{\mathrm{bF}}$ & 64,14 & 30,86 & $0,02^{\mathrm{bF}}$ \\
\hline
\end{tabular}

Tablo 3. Okluzal düzlem eğimin değiş̧iminin gruplara göre ortalama, standart sapma ve anlamlılık değerleri.

\begin{tabular}{|c|c|c|c|c|c|c|c|c|c|}
\hline & \multicolumn{3}{|c|}{ 1. Sınıf Öğrencileri } & \multicolumn{3}{|c|}{ 5. Sınıf Öğrencileri } & \multicolumn{3}{|c|}{ Jzman Diş Hekimleri } \\
\hline & Ort. & $\mathrm{SD}$ & $p$ & Ort. & $\mathrm{SD}$ & $p$ & Ort. & SD & $p$ \\
\hline Fotoğraf a & 34,25 & 22,21 & $0,15^{\mathrm{aA}}$ & 41,52 & 23,51 & $0,09^{\mathrm{aB}}$ & 23,65 & 23,18 & $0,12^{\mathrm{aC}}$ \\
\hline otoğraf b & 35,16 & 24,87 & $0,21^{\mathrm{aB}}$ & 40,90 & 22,15 & $0,24^{\mathrm{aB}}$ & 24,51 & 24,71 & $0,31^{\mathrm{aC}}$ \\
\hline Fotoğraf c & 34,48 & 21,91 & $0,26^{\mathrm{aC}}$ & 42,02 & 21,74 & $0,41^{\mathrm{aD}}$ & 33,33 & 25,97 & $0,14^{\mathrm{aC}}$ \\
\hline Fotoğraf d & 50,11 & 23,45 & $0,05^{\mathrm{bD}}$ & 44,36 & 22,03 & $0,22^{\mathrm{aE}}$ & 34,84 & 25,27 & $0,09^{\mathrm{aF}}$ \\
\hline Fotoğraf e & 52,45 & 26,24 & $0,09^{\mathrm{bE}}$ & 59,95 & 25,47 & $0,10^{\mathrm{bE}}$ & 61,83 & 23,48 & $0,18^{\mathrm{bE}}$ \\
\hline Fotoğraf f & 58,42 & 22,51 & $0,06^{\mathrm{cF}}$ & 61,32 & 19,84 & $0,09^{\mathrm{bG}}$ & 64,52 & 27,67 & $0,04^{\mathrm{bF}}$ \\
\hline
\end{tabular}

Büyük harfler yatay anlam/ılığı, küçük harfler dikey anlam/ılığı belirtmektedir.

Gummy smile değişiminin değerlendirildiği fotoğraflarda en düşük VAS değeri gummy smile miktarının 2,5 mm olduğu orijinal fotoğraflarda bulunurken, en yüksek değerler $2 \mathrm{~mm}$ ve $2,5 \mathrm{~mm}$ diş eti görünümünün azaltıldığı fotoğraflarda bulunmuştur (Tablo 4). Gruplar arasında istatiksel olarak anlamlı fark bulunmazken, tüm grupların fotoğrafları arasında istatiksel olarak anlamlı fark bulunmuştur.

Tablo 4. Gummy smile değişiminin gruplara göre ortalama, standart sapma ve anlamlılık değerleri.

\begin{tabular}{|c|c|c|c|c|c|c|c|c|c|}
\hline & \multicolumn{2}{|c|}{$\begin{array}{l}1 . \\
\text { Öğrencileri }\end{array}$} & \multirow{2}{*}{$\begin{array}{c}\text { Sinıf } \\
p\end{array}$} & \multicolumn{2}{|c|}{$\begin{array}{l}5 . \\
\text { Öğrencileri }\end{array}$} & & \multicolumn{2}{|c|}{$\begin{array}{l}\text { Uzman } \\
\text { Hekimleri }\end{array}$} & Diş \\
\hline & Ort. & SD & & Ort. & SD & $p$ & Ort. & SD & $p$ \\
\hline Fotoğraf a & 23,45 & 22,21 & $0,09^{\mathrm{aA}}$ & 22,25 & 17,16 & $0,10^{\mathrm{aB}}$ & 24,65 & 14,63 & $0,08^{a C}$ \\
\hline Fotoğraf b & 24,84 & 15,58 & $0,11^{\mathrm{aB}}$ & 24,99 & 21,65 & $0,09^{\mathrm{aB}}$ & 24,45 & 21,17 & $0,17^{a c}$ \\
\hline Fotoğraf c & 35,62 & 20,71 & $0,12^{\mathrm{bC}}$ & 36,82 & 19,75 & $0,13^{\mathrm{aC}}$ & 29,62 & 19,56 & $0,06^{a C}$ \\
\hline Fotoğraf $\mathrm{d}$ & 42,12 & 19,54 & $0,08^{\mathrm{bD}}$ & 41,85 & 25,33 & $0,09^{\mathrm{aD}}$ & 31,52 & 23,52 & $0,21^{\mathrm{aD}}$ \\
\hline Fotoğraf e & 74,27 & 16,21 & $0,07^{\mathrm{CE}}$ & 70,25 & 26,20 & $0,15^{\mathrm{bE}}$ & 68,35 & 21,26 & $0,16^{\mathrm{bE}}$ \\
\hline Fotoğraf f & 73,52 & 15,25 & $0,05^{\mathrm{CF}}$ & 69,22 & 18,42 & $0,06^{\mathrm{bF}}$ & 70,27 & 23,93 & $0,09^{\mathrm{bF}}$ \\
\hline
\end{tabular}

\section{TARTIŞMA}

Görsel analog skalası, ağrının subjektif ölçümünde kullanılan doğru, güvenilir ve tekrar edilebilen özellikteki basit bir yöntemdir ${ }^{20}$. Birçok 
araştırmacı görsel analog skalası ile estetik skorlama yaparak kabul edilebilir çekiciliğin değerlendirmesinde kullanılabilecek basit,kolay uygulanabilir ve hızlı bir yöntem olduğunu söylemişlerdir ${ }^{12,21}$. Estetik algıdaki farlıı̆ı belirlemek için de görsel analog skalasından yararlanılmıştır.

Saç rengi, yüzün şekli, cilt rengi ve cinsiyet gibi yüz özelliklerini etkileyen faktörler insanlardaki estetik gülümsemenin algılanmasında görsel dikkat seviyesi üzerinde potansiyel etkisi olan faktörlerdir ${ }^{7,22}$.

Estetik bölgede ki asimetriler özellikle ortodontik tedavi hastalarında yaygın bir şekilde mevcuttur ${ }^{1,23}$. Buna göre, birçok çalışma rehabilitasyon tedavilerinde klinisyenlere yardımcı olabilecek estetik referansları belirlemeyi amaçlamaktadır ${ }^{1}{ }^{24}$. Yapılan çalışmalara göre halktan bireyler ile diş hekimleri arasındaki estetik parametrelerin değerlendirilmesinde farklılıklar olduğu gözlenmiştir ${ }^{25}$. Ortodontik ve protetik diş tedavisi gibi dental tedavilerde hastaların estetik algılarıyla hekim algılarının farklılık göstermesi sebebiyle değerlendirmenin çift yönlü yapılması daha uygundur.

Bununla birlikte, herhangi bir oral, dişeti veya diş özelliklerinin değerlendirilmesinde halktan kişilerin algısının, kendi aralarında ve ayrıca diş hekimleri arasında büyük ölçüde değişebileceğini düşünmek önemlidir. Bu nedenle, herhangi bir estetik diş tedavisindeki karar verme süreci hastanın görüşünü içermelidir.

Kokich ve $\operatorname{ark}^{13}$ yaptığı çalışmaya göre ortodontistler, genel diş hekimlerine göre, değişen estetik oranların algılanmasında daha kritik değerler vermiştir. Genel popülasyonun, diş hekimlerinden daha az estetik farkındalığa sahip olduğu gözlenmiştir. Ortodontistlere göre en etkileyici gülümseme yüz ve diş oranlarının simetrik olduğu gülümseme olarak belirtilmiştir $^{26}$. Bu yüzden çalışmamızda diş hekimliği uzmanlık alanlarıyla diş hekimliği öğrencilerinin artan eğitim düzeyleriyle estetik algılarının değişkenliğinin karşılaştırılması yapılmıştır.

Frontal perspektiften bakıldığında interpupillar düzlem, okluzal düzlem eğimlerinin belirlenmesinde referans olarak yaygın kullanılan konvansiyonel bir çizgidir $^{16,}{ }^{27-30}$. Buna rağmen yazarlar komissural düzlemin okluzal düzlemin eğimine referans olarak kullanılabileceği yayınlardan habersizdirler. Yapılan bir çalışmaya göre halktan insanlar komissural düzlem, interpupillar düzlem ve okluzal düzlem eğimlerinin birbirlerin paralel olan simetrik yüzleri tercih etmişlerdir ${ }^{31}$. Yine aynı çalışmaya göre interpupillar ve komissural paralelliklerdeki dengesizlikler de hastalar okluzal düzlemin eğiminin comissural düzlem ile aynı düzlemde olmasını daha tercih edilebilir bulmuştur ${ }^{31}$. Bu çalışmada da sonuçlar okluzal düzlemdeki $2,5 \mathrm{~mm}$ eğimlerin bile fark edilemediğini göstermiştir.

Gülümseme estetiğini etkileyen gingiva görünürlüğün derecesi değişkendir ${ }^{13}$. Genç bir gülümsemenin özellikleri; maksiller keser dişlerin tam görünümüyle birlikte, 1-2 mm dişeti görünürlüğüne sahip olmalıdı². Gingivanın aşırı görünürlüğü `gummy smile" olarak bilinir ve gülümsemeyi itici kılmaktadır ${ }^{33}$.

Kadınlarda daha genç bir görünüm sağlayan 12 mm'lik yüksek gülme hatlı dişeti görünümü daha belirgindir ve daha estetik olarak algılanmaktadır. Ortodontik tedavi gören hastalar üzerinde yapılan bir çalışmada, gülümseme sırasında $2 \mathrm{~mm}$ ve daha fazla maksiller dişeti görünümünün \% 26 oranında olduğu bildirilmiştir $^{18}$. Yapılan diğer bir çalışmada $2 \mathrm{~mm}^{\prime}$ lik dişeti görünümünün ortodontistler ve diş hekimliği öğrencileri tarafından çekici olarak algılanmadığı gözlenmiştir ${ }^{34}$. Al Taki ve ark.'nın yaptığı çalışmaya göre 2 mm'lik dişeti görünümünün ortodontistler tarafından çekici olarak kabul edilmekle birlikte, 4 mm'lik dişeti görünümünün halktan bireyler için çekici bir görünüş olarak kabul edilmektedir ${ }^{35}$. Bu çalışmayı destekler nitelikte 2,5 mm'lik dişeti görünümü hiçbir grup tarafından estetik bulunmamıştır.

Ouseal ve ark.'nın maksiller santral dişlerinin kron boylarını modifiye ettikleri çalışmalarında değişimin $2 \mathrm{~mm}$ den az olduğu sonuçlarda halktan bireyler ve profesyoneller arasında anlamlı farklılık gözlenmiştir ${ }^{36}$. Kron uzunluklarının asimetrik olarak değiştirildiği çalışmalarda dental profesyoneller ve halktan bireyler arasındaki farklılığın anlamlı olarak belirginleştiği gözlenmiştir ${ }^{13,19}$. Bizim çalışmamızda bu çalışmaları destekler nitelikte olup, santral dişlerin uzunluklarının 2, 2.5mm arttırıldığı fotoğraflar ile orijinal fotoğraflar arasında anlamlı farklılıklar tespit edilmiştir.

Silva ve ark'nın ${ }^{31}$, halktan bireyler arasında yaptığı çalışmalarda tranvers okluzal düzlemin, interpupiller düzlem ve komissural düzlem ile paralel oldukları simetrik gülümsemeleri tercih etmişlerdir. Katılımcıların \%70 'i komissural düzlem ile transvers okluzal düzlem eğimlerinin paralel oldukları resimlerin daha çekici olduğunu kabul etmişlerdir ${ }^{31}$. Bizim çalışmamızda da bu çalışmaya benzer nitelikte okluzal düzlem eğiminin komissural düzlem eğimine paralel hale getirilmesiyle daha çekici gülümsemeler elde edildiği gözlenmiştir, fakat katılımcılar arasında okluzal düzlem eğimlerinin değiştirildiği fotoğraflarda değerlendirme yapılması ilk bakışta zor olmuştur. 
İnsanların keser düzlemindeki eğimi $3 \mathrm{~mm}$ olana kadar fark edemediklerini ve dişeti görünümünün 4 mm olduğunda çekici olmadığını fark ettiklerini bildirmişlerdir ${ }^{7}$. Van der Geld ve arkadaşlarının ${ }^{4}$ yaptığı çalışmada, katılımcılar 2-4 mm aralığındaki gülümseme hattı yüksekliğini tercih etmişlerdir. Suudi diş hekimleri ve halktan bireyler üzerinde yapılan çalışmada 1 mm'den fazla olan gummy smile olgularında çekiciliğin azaldığı sonucuna varmışlardır ${ }^{19}$.

\section{SONUÇLAR}

1. Çalışmada bireyler arasındaki estetik algının eğitim seviyesiyle doğru orantılı olarak değiştiği ve uzman diş hekimlerinin değişimlere daha duyarlı olduğu görülmüştür.

2. Gummy smile, orta hat sapması ve santral dişlerin oranındaki değişimler çalışmaya katılan bireyler tarafından daha net bir şekilde saptanırken, okluzal düzlem eğimindeki değişimin saptanması zor olmuştur.

3. Bireylerdeki estetik algı $2 \mathrm{~mm}$ ve daha yüksek değişim oranlarında daha ön plana çıkmıştır.

İleri ki çalışmalarda diş hekimliği uzmanlık dalları arasında estetik algının değişimlerinin değerlendirilmesiyle birlikte cinsiyetler arasındaki estetik algı değiş̧imlerinin değerlendirmesi yapılabilir.

NOT: Çalışmada herhangi bir yazar, kurum ya da kurulus ile çıkar çatışması içerisinde bulunmamaktadır. Makale daha önce hiçbir yerde yayınlanmamış ve yayınlanmak üzere işlem görmemektedir

\section{KAYNAKLAR}

1. Machado AW, Moon W, Gandini LG, Jr. Influence of maxillary incisor edge asymmetries on the perception of smile esthetics among orthodontists and laypersons. Am J Orthod Dentofacial Orthop May 2013;143:658-64.

2. McLeod C, Fields HW, Hechter F, Wiltshire W, Rody W, Jr., Christensen J. Esthetics and smile characteristics evaluated by laypersons. Angle Orthod Mar 2011;81:198-205.

3. Nascimento DC, Santos ER, Machado AW, Bittencourt MAV. Influence of buccal corridor dimension on smile esthetics. Dental Press J Orthod 2012;17:145-50.
4. Van der Geld P, Oosterveld P, Van Heck G, Kuijpers-Jagtman AM. Smile attractiveness. Selfperception and influence on personality. Angle Orthod Sep 2007;77:759-65.

5. Koidou VP, Rosenstiel SF, Rashid RG. Celebrity smile esthetics assessment: Smile angulation. J Prosthet Dent 2017;117:636-41.

6. Tjan AH, Miller GD, The JG. Some esthetic factors in a smile. J Prosthet Dent 1984;51:24-8.

7. Kokich VO, Jr., Kiyak HA, Shapiro PA. Comparing the perception of dentists and lay people to altered dental esthetics. J Esthet Dent 1999;11:311-24.

8. Abu Alhaija ESJ, Al-Shamsi NO, Al-Khateeb S. Perceptions of Jordanian laypersons and dental professionals to altered smile aesthetics. Eur J Orthodont 2011;33:450-6.

9. Ker AJ, Chan R, Fields HW, Beck M, Rosenstiel S. Esthetics and smile characteristics from the layperson's perspective A computer-based survey study. J Am Dent Assoc 2008;139:1318-27.

10. Parekh SM, Fields HW, Beck M, Rosenstiel S. Attractiveness of variations in the smile arc and buccal corridor space as judged by orthodontists and laymen. Angle Orthod 2006;76:557-63.

11. Rodrigues CDT, Magnani R, Machado MSC, Oliveira $\mathrm{OB}$. The perception of smile attractiveness variations from esthetic norms, photographic framing and order of presentation. Angle Orthod 2009;79:634-9.

12. Krishnan V, Daniel ST, Lazar D, Asok A. Characterization of posed smile by using visual analog scale, smile arc, buccal corridor measures, and modified smile index. Am J Orthod Dentofac Orthop 2008;133:515-23.

13. Kokich VO, Kokich VG, Kiyak HA. Perceptions of dental professionals and laypersons to altered dental esthetics: asymmetric and symmetric situations. Am J Orthod Dentofacial Orthop Aug 2006;130:141-51.

14. Rosenstiel SF, Rashid RG. Public preferences for anterior tooth variations: a web-based study. J Esthet Restor Dent 2002;14: 97-106.

15. Pinho S, Ciriaco C, Faber J, Lenza MA. Impact of dental asymmetries on the perception of smile esthetics. Am J Orthod Dentofac Orthop Dec 2007;132:748-53.

16. Chiche G, Pinault A. Artistic and scientific principles applied to esthetic dentistry. Esthetic Anterior Fixed Prosthod Quintessence 1994:13-32. 
17. Silva BP, Jimenez-Castellanos E, Martinez-deFuentes R, Greenberg JR, Chu S. Laypersons' perception of facial and dental asymmetries. Int J Periodont Res Dent 2013;33:e162-71.

18. Peck S, Peck L. Selected aspects of the art and science of facial esthetics. Semin Orthod 1995; 1:105-26.

19. Talic N, Alomar S, Almaidhan A. Perception of Saudi dentists and lay people to altered smile esthetics. Saudi Dent J 2013;25:13-21.

20. Ohnhaus EE, Adler R. Methodological problems in measurement of pain - comparison between verbal rating scale and visual analog scale. Pain 1975; 1:379-384.

21. Ritter DE, Gandini LG, Pinto Ados S, Locks A. Esthetic influence of negative space in the buccal corridor during smiling. Angle Orthod 2006;76:198203.

22. Richards MR, Fields HW, Jr., Beck FM, et al. Contribution of malocclusion and female facial attractiveness to smile esthetics evaluated by eye tracking. Am J Orthod Dentofac Orthop 2015; 147:472-82.

23. Machado AW. 10 commandments of smile esthetics. Dental Press J Orthod 2014;19:136-57.

24. Correa BD, Vieira Bittencourt MA, Machado AW. Influence of maxillary canine gingival margin asymmetries on the perception of smile esthetics among orthodontists and laypersons. Am J Orthod Dentofac Orthop 2014;145:55-63.

25. Flores-Mir C, Silva E, Barriga MI, Lagravere MO, Major PW. Lay person's perception of smile aesthetics in dental and facial views. J Orthod 2004; 31:204-9.

26. Ribeiro JB, Figueiredo BA, Machado AD. Does the presence of unilateral maxillary incisor edge asymmetries influence the perception of smile esthetics? J Esthet Res Dent 2017; 29:291-7.

27. Fradeani M. Esthetic rehabilitation in fixed prosthodontics. vol. 1. Esthetic analysis: a systematic approach to prosthetic treatment. Quintessence 2004:35-61.

28. Fradeani $M$. Esthetic rehabilitation in fixed prosthodontics. vol 1. Esthetic analysis: a systematic approach to prosthetic treatment. Quintessence 2004; 63-11.

29. Fradeani M. Evaluation of dentolabial parameters as part of a comprehensive esthetic analysis. Eur J Esthet Dent 2006;1:62-9.
30. Rufenacht CR. Fundamentals of esthetics. Hanover Park: Quintessence 1990:67-134.

31. Silva BP, Jimenez-Castellanos E, Finkel S, Macias IR, Chu SJ. Layperson's preference regarding orientation of the transverse occlusal plane and commissure line from the frontal perspective. J Prosthet Dent 2017;117:513-6.

32. Sarver DM. Principles of cosmetic dentistry in orthodontics: Part 1. Shape and proportionality of anterior teeth. Am J Orthod Dentofac Orthop 2004;126:749-53.

33. Üner $D D$, İzol BS, İpek $F$, Elbir $M$, Tosun $B$. Dudağın yeniden konumlandırılması ve gingivektomi yapılarak gummy smile tedavisi bir olgu sunumu (Gummy smile). J Dent Fac Atatürk Uni 2015;10:25-9.

34. Ioi $H$, Nakata $S$, Counts AL. Influence of gingival display on smile aesthetics in Japanese. Eur J Orthod 2010;32:633-7.

35. Al Taki A, Khalesi M, Shagmani M, Yahia I, Al Kaddah F. Perceptions of altered smile esthetics: a comparative evaluation in orthodontists, dentists, and laypersons. Int J Dent 2016;2016:7815274.

36. Ousehal L, Aghoutan H, Chemlali S, Anssari IF, Talic N. Perception of altered smile esthetics among Moroccan professionals and lay people. Saudi Dent J 2016;28:174-82.

\author{
Yazışma Adresi \\ Prof. Dr. Nuran YANIKOĞLU \\ Atatürk Üniversitesi \\ Diş Hekimliği Fakültesi \\ Protetik Diş Tedavisi AD, Erzurum \\ E-mail: nyanikoglu@yahoo.com
}

